\title{
Failure Mode of Implant Abutment Connections -An Overview
}

\author{
Aashritha Shenava ${ }^{1}$ \\ ${ }^{I}$ (Department of Prosthodontic/A B Shetty Institute of Dental Sciences/Nitte University /India)
}

\begin{abstract}
The use of single tooth implant restoration in anterior and lateral regions is increasing . Replacing single missing teeth especially in the anterior region has always been a challenge for clinicians and dental technicians. With the advent of single tooth implant restoration; an acceptable alternative is identified .Implant abutment must meet biological, functional and esthetic requirements. Biological and mechanical implantabutment connection complications and failures are still present in clinical practice, frequently compromising oral function. Abutment screw loosening has occurred with many of other designs used for single tooth implant .The purpose of this review is to highlight the mode of failure as well as the reasons. Clinical cases, experimental and non-experimental studies were included, as well as literature reviews.
\end{abstract}

Key words: Dental implant; Implant-abutment connection; Failure mode

\section{Introduction:}

It is a challenge for dentists with the upcoming treatment modalities. As a result of increasing patient demands, removable partial dentures have become less acceptable, and many patients oppose the preparation of intact teeth for the fabrication of a fixed partial denture. Alternatives to conventional fixed or removable partial dentures have been resin bonded fixed partial dentures, orthodontic movement to eliminate spacing, and transplantation of teeth into the space of the missing teeth. Unfortunately, these alternatives either lacked predictability or were esthetically and functionally unacceptable. With the advent of the single-tooth implant restoration, an acceptable alternative was identified. The clinical efficacy of osseointegrated implants for singletooth replacement has been documented extensively.[1-4] Functionally, the abutment must provide sufficient strength to transmit forces to the implant and the bone.[5 ]Abutment screw loosening has occurred with many of the early designs used for single-tooth implant restorations.[6-8].Abutment -Implant interphase is always been a topic of debate and the failure mode of the interphase are caused due to numerous reasons.

\section{Classification Of Implant-Abutment Connection Designs:}

Within the same basic setup, manufacturers have developed various implant-abutment connection designs. These interface designs can be roughly divided into two groups.

2.1The first group may be described as butt joints or slip fit joints, with a passive connection and a slight space between implant and abutment.[9]

\subsection{The second group comprises conical interface designs with friction fit joints}

Both types can be subclassified into internal and external connection types. With the internal connection type, connective parts of the abutment are placed into the implant body. In contrast, an external connection type is observed when connective parts of the abutment enclose an extension of the implant body. The different implant-abutment connection designs can also be classified with respect to the lock against rotation by an index at the implant-abutment interface. An index is useful in transferring the model cast situation to the in vivo situation by avoiding displacement and rotation of abutment in the fixture. Norton compared the indexed internal conical interface connection of the Astra Tech (AST) system with $\mathrm{Br}^{\circ}$ anemark's hexindexed butt joint connection and found that the internal conical interface exhibited increased resistance to bending moments at the fixture/abutment interface. M"ollersten et al also investigated various implant systems with different joint designs and reported that deep joints exhibited better load bearing capacity than connections with a relatively short overlap of implant and abutment.

To avoid technical complications during function, one major requirement is a high load-bearing capacity of the implant and its components. A systematic review revealed that technical complications related to implant components and superstructures were reported in $60 \%$ to $80 \%$ of the studies included, whereas the fixture failed in less than $1 \%$ of the cases in vivo. Implant overload was responsible for cracks developing in the material, leading to catastrophic failure even after short periods of function. Failure may also be the result of material fatigue when subcritical slow crack growth develops below the material's yield strength due to cyclic chewing forces. All these complications eventually result in time-consuming and complex treatment, which in the worst case of fixture fracture may end with a large bone defect after explantation. [10] 


\section{Factors Effecting The Implant Abutment Interface:}

The structural integrity and biologic compatibility of the implant abutment interface and thereby that of the implant prosthesis depends on the following factors.

3.1Implant abutment interface geometry/design

3.2Micromotion

3.3Screw mechanics

3.4Platform switching

\subsection{IMPLANT ABUTMENT INTERFACE GEOMETRY/DESIGN}

The original Brånemark protocol required several externally hexed implants to restore fully edentulous arches, linking them together via a metal bar with a fixed prosthesis. Dr. Gerald A Niznick was the first one to suggest modification to the Implant abutment design in the form of internal hex. In internal hex connection the mating components are situated inside the implant body which was believed to help in better stress distribution and provide better and more prosthetic options. Almost all vitro studies [11-14], with the exception of one, have demonstrated that internal connections have greater stability than external hex connections. The next major advancement in terms of geometry of the connection was the introduction of tapered connections. Tapered connections are believed to give better marginal seal and reduce the micro movements between the implant and the abutment. A conical implant-abutment interface at the level of the marginal bone is also believed to improve the distribution of the load into the supporting bone. But titanium conical abutments appear to have poorer load fatigue performance compared with external-hexagon connections. [15] In reduced-diameter conical connections, the neck of this implant is a potential zone for fracture when subjected to high bending forces. The joined surfaces may also incorporate a rotational resistance and indexing feature and/or lateral stabilizing geometry. This geometry is further described as octagonal, hexagonal, cone screw, cone hex, cylinder hex, cam tube, and pin/slot. Combination of morse taper with other features such as internal hex is also being tried in newer implant systems. Some screw less implant systems which rely entirely on the friction fit for their stability are also available - Eg: Bicon.

\subsection{MICROGAP AND MICROMOTION}

Three main factors have been identified as possible causes for the formation of microgaps: occlusal load during physio-logical function, manufacturing tolerance and micromotion between the implant-abutment connection. Different types of abutment connections have been reported to produce different magnitudes of micromotion.[16,17]Two major types of abutment connections are the conical and the butt-joint, the latter type of connection being available in at least three different forms: hexagonal, octagonal and trilobe. The design configuration of the abutment connection also plays a vital role in uniformly transferring occlusal stresses to the bone, thus eliminating potential microgap formation due to uneven loading.[18] The sharp angles and vertices at abutment connections induce high stresses, causing wear, and therefore causing microgap formation.[19] Micromotion and stress are believed to play pivotal roles in microgap formation and microbial leakage. Different designs of implant-abutment connections are predicted to induce different patterns of micromotion and stress distribution under occlusal loading.

\subsection{SCREW MECHANICS}

Mc Glumphy et al defined the screw joint as 2 parts tightened together by a screw, such as an abutment and implant being held together by a screw.A screw is tightened by applying torque. The applied torque develops a force within the screw called the pre-load. As a screw is tightened, it elongates, producing tension. Elastic recovery of the screw pulls the 2 parts together, creating a clamping force.[20]

The preload in the screw, from elongation and elastic recovery, is equal in magnitude to the clamping force.Opposing the clamping force is a joint separating force, which attempts to separate the screw joint. Screw loosening occurs when the joint-separating forces acting on the screw joint are greater than the clamping forces holding the screw unit together.Excessive forces cause slippage between threads of the screw and threads of the bore,resulting in a loss of preload.[21] When the clinician applies a torque to a screw to tighten its components together, the tightening torque creates a preload in the screw. The preload is determined by the applied torque and other factors, such as the screw alloy, screw head design, and abutment surface. The established preload is proportional to the applied torque. The torque value can be controlled by the clinician and can be reproduced from implant prosthesis to implant prosthesis.Too little torque may allow separation of the joint and result in screw fatigue, loosening, and failure. Too large a torque may strip the screw threads.Increasing the torque will increase the preload. Increasing the preload maximizes the stability of the screw joint by increasing the clamping threshold that separating forces must overcome to cause screw loosening.

The amount of torque than can be applied is limited by the ultimate strength of the screw. McGlumphy et al have stated that the optimal torque value is $75 \%$ of the torque needed to cause screw failure.Another 
variable in the amount of torque that can be applied is how the torque is produced by the clinician.Torque can be applied manually or with a mechanical device. Until the introduction of mechanical torquing devices to the profession, implant components were tightened manually. The inexperienced clinician often undertightened the screws in an implant system. Dellinges and Tebrock[22] found that the average torque applied with a screwdriver is only $10 \mathrm{~N}-\mathrm{cm}$. In a pilot study, Jaarda et al [23] found that test subjects with little implant experience were not generally able to provide the recommended torque to implant prosthesis-retaining slotted gold screws.

\subsection{Platform switching}

The peri-implant bone level has been used as one of the criteria to assess the success of dental implants. The peri-implant bone remodeling occurs once the implant is exposed to the oral environment in a second surgical procedure or when the abutment is placed immediately after implant placement.[24-26]

The concept of platform switching was not fully understood and several theories were suggested to explain this phenomenon. The biomechanical theory proposed that connecting the implant to a smaller diameter abutment may limit bone resorption by shifting the stress-concentration zone away from the crestal boneimplant interface and directing the forces of occlusal loading along the axis of the implant.[27] One theory assumed that shifting the implant-abutment connection may medialize the location of the biologic width and minimize the marginal bone resorption. This theory was based on previous studies $[28,29]$ that showed that placing the implant-abutment junction (IAJ) at or below the crestal bone level may cause vertical bone resorption to reestablish the biologic width. Another theory concerned the role of the inflammatory cell infiltrate at the IAJ. Regardless of the nature of the peri-implant inflammatory infiltrate, the physical repositioning of the IAJ away from the external outer edge of the implant and neighbouring bone may limit bone resorption by containing the inflammatory cell infiltrate within the angle formed at the interface away from the adjacent crestal bone.

\section{Conclusion}

According to this literature review, one can conclude that with a conical implant-abutment interface at the level of the marginal bone, in combination with retention elements at the implant neck, and with suitable values of implant wall thickness and modulus of elasticity, the amount of micromotion can be reduced to a greater extend thereby improving joint stability and success of the implant therapy. The tightening torque is an important factor to improve mechanical and biological properties of the interface between implant and abutment and the use of the torque recommended from the manufacturer may potentially reduce the adverse effects of microleakage. The concept of platform switching appears to limit crestal resorption and seems to preserve periimplant bone levels.

\section{References}

[1]. Schmitt A, Zarb GA. The longitudinal clinical effectiveness of osseointegrated dental implants for single-tooth replacement. Int $J$ Prosthodont $6,1993,197-202$.

[2]. Carter GM, Hunter KM. Implant-based treatment for the loss of a single tooth. N Z Dent J 90,1994,150-156.

[3]. Cordioli G, Castagna S, Consolati E. Single-tooth implant rehabilitation. A retrospective study of 67 implants. Int J Prosthodont 7,1994,525-531.

[4]. McMillan AS, Allen PF, Bin Ismail I. A retrospective multicenter evaluation of single tooth implant experience at three centers in the United Kingdom. J Prosthet Dent 79,1998,410-414.

[5]. Tripodakis AP, Strub JR, Kappert HF, Witkowski S. Strength and mode of failure of single implant all-ceramic abutment restorations under static load. Int J Prosthodont 8,1995,265-274.

[6]. Jemt T, Laney WR, Harris D, et al. Osseointegrated implants for single-tooth replacement: A 1-year report from a multicenter prospective study. Int J Oral Maxillofac Implants 6,1991,29-36.

[7]. Jemt T, Pettersson P. A 3-year follow-up study on single implant treatment. J Dent 21,1993,203-208.

[8]. Ekfeldt A, Carlsson GE, Börjesson G. Clinical evaluation of singletooth restorations supported by osseointegrated implants: A retrospective study. Int J Oral Maxillofac Implants 9, 1994,179-183.

[9]. Binon P: Evaluation of three slip fit hexagonal implants. Implant Dent 5,1996,235-248

[10]. Morgan MJ, James DF, Pilliar RM: Fractures of the fixture component of an osseointegrated implant. Int J Oral Maxillofac Implants 8,1993,409-414

[11]. Balfour A, O’Brien GR.Comparative study of antirotational single tooth abutments. J Prosthet Dent 73,1995,36-43.

[12]. Norton MR.An in-vitro evaluation of the strength of an internal conical interface compared to a butt joint interface in implant design. Clin Oral Implant Res 8,1997,290-298.

[13]. Weiss EI,Kozak D, Gross MD.Effect of repeated closures on opening torque values in seven abutment-implant systems. $J$ Prosthet Dent 84,2000,194-199.

[14]. Piermatti J,Yousef H, Luke A,Mahevich R,Weiner S. An in vitro analysis of implant screw torque loss with external hex and internal connection implant systems. Implant Dent 15,2006,427-432.

[15]. Kivang Akga. Evaluation of the mechanical characteristics of the implant-abutment complex of a reduced-diameter morse-taper implant - finite element stress analysis. Clin. Oral Impl Res. 14,2003,444-454

[16]. Steinebrunner L, Wolfart S, Bo "bmann K, Kern M. In vitro evaluation of bacterial leakage along the implant-abutment interface of different implant systems. International Journal of Oral \& Maxillofacial Implants 20,2005,875-81. 
[17]. Zipprich H, Weigl P, Lange B, Lauer HC. Micromovements at the implant-abutment interface: measurement, causes, and consequences. Implantologie 15,2007,31-46.

[18]. Segundo RM, Oshima HM, da Silva IN, Burnett Jr LH, Mota EG, Silva LL. Stress distribution of an internal connection implant prostheses set: a 3D finite element analysis.Stomatologija Baltic Dental and Maxillofacial Journal 11,2009,55-9.

[19]. Segundo RM, Oshima HM, Silva IN, Ju' nior LH, Mota EG, Coelho LF. Stress distribution on external hexagon implant system using 3D finite element analysis. Acta Odontolol Latinoamericana 20,2007,79-81.

[20]. McGlumphy EA, Mendel DA,Holloway JA. Implant screw mechanics.Dent Clin N Am.42,199871-89.

[21]. Lang LA, May KB, Wang RF.The effect of the use of a counter torque device on the abutment-implantcomplex. $J$ Prosthet Dent $81,1999,411-417$

[22]. Dellinges MA, Tebrock OC. A measurement of torque values obtained with hand-held drivers in a simulated clinical setting. Int J Prosthodont. 2,1993,212-214.

[23]. Jaarda MJ, Razzoog ME, Gratton DG. Providing optimum torque to implant prostheses: a pilot study. ImplantDent.2, 1993,50-52.

[24]. Albrektsson T, Zarb G, Worthington P, Eriksson AR. The long-term efficacy of currently used dental implants: A review and proposed criteria of success. Int J Oral Maxillofac Implants 1,1986,11-25.

[25]. Albrektsson T, Isidor F. Consensus report of session IV. In: Lang NP, Karring T, eds.Proceedings of the $1^{\text {st }}$ European Workshop on Periodontology. London: Quintessence Publishing; 1994:365-369.

[26]. Misch CE, Perel ML, Wang HL, et al. Implant success, survival, and failure: the International Congress of Oral Implantologists (ICOI) Pisa Consensus Conference. Implant Dent 15,2008,5-15.

[27]. Maeda Y, Miura J, Taki I, Sogo M. Biomechanical analysis on platform switching: Is there any biomechanical rationale? Clin Oral Implants Res 18,2007,581-584.

[28]. Hermann JS, Schoolfield JD, Nummikoski PV, Buser D, Schenk RK, Cochran DL. Crestal bone changes around titanium implants: A methodologic study comparing linear radiographic with histometric measurements. Int J Oral Maxillofac Implants 16,2001,475485 .

[29]. Todescan FF, Pustiglioni FE, Imbronito AV, Albrektsson T, Gioso M. Influence of the microgap in the peri-implant hard and soft tissues: A histomorphometric study in dogs. Int J Oral Maxillofac Implants 17,2002,467-472. 